\title{
A CONSTRUÇÃO DO CONCEITO DE TEMPO EM SALA DE AULA: ANÁLISE SOBRE AS EXPERIÊNCIAS DE PROFESSORES DE HISTÓRIA DA REDE MUNICIPAL E ESTADUAL DE ENSINO DE BRASILÂNDIA/MS NA PERSPECTIVA DA EDUCAÇÃO HISTÓRICA.
}

\author{
Anilton Diogo dos Santos, Marlene Rosa Cainelli
}

Universidade Estadual de Londrina - UEL, Mestrado, Londrina, PR. E-mail: diogo icaro18@yahoo.com.br.

\section{RESUMO}

O presente artigo, faz parte do projeto de pesquisa em andamento no programa de mestrado em Educação da Universidade Estadual de Londrina, alocada na linha: Perspectivas Filosóficas, Históricas e Políticas da Educação e no núcleo: História da Educação e Ensino de História, sob a orientação da professora doutora Marlene Rosa Cainelli. As leituras e reflexões para essa investigação articulam-se ao campo da Educação Histórica. Nossa pesquisa, ainda que inicial, tem como foco como professores de história do Município de Brasilândia no Mato Grosso do Sul concebem, organizam e utilizam-se dos conceitos de tempo e temporalidade no exercício de sua docência. Para construir essa reflexão embasaremos nossas ações em uma abordagem qualitativa com triangulação de dados, em que pretendemos por meio de entrevistas com os professores traçar um perfil destes profissionais no que tange sua formação profissional e conceitual, para então buscarmos entender como ocorre a construção dos conceitos que esses usam em suas atividades docentes. Outro momento consistirá em analisar planejamentos e observar a aplicação destes em aulas de história. Por fim através da leitura das atividades (presentes nos planejamentos) e das avaliações desenvolvidas por esses professores, em sala de aula, identificaremos os múltiplos conhecimentos sobre tempo e temporalidade. Entender qual a formação teórica, como esses professores fazem suas escolhas metodológicas e como a partir dos conceitos de temporalidade elaboram seu currículo informal (aquele elaborado no cotidiano da ação docente no processo ensino/aprendizagem), pode auxiliar a entender como se desenvolve este processo de ensino aprendizagem.

Palavras-chave: Ensino de História; Educação Histórica, Cultura escolar; Tempo e Temporalidade Histórica.

\section{THE CONSTRUCTION OF THE CONCEPT OF TIME IN CLASSROOM: ANALYSIS OF THE EXPERIENCES OF HISTORY TEACHERS THE MUNICIPAL AND STATE SCHOOL SYSTEM BRASILÂNDIA/MS FROM THE PERSPECTIVE OF HISTORY EDUCATION}

\begin{abstract}
The present article, is part of the research project in process in the master's degree program in Education of the State University of Londrina, allocated in the line: Perspectives Philosophical, Historical and Politics of the Education and in the nucleus: History of the Education and Teaching of History, under the teacher's orientation Marlene Rosa Cainelli. The readings and reflections for that investigation pronounce to the field of the Historical Education. Our research, although initial, has as focus as teachers of history of the Municipal district of Brasilândia in Mato Grosso do Sul becomes pregnant, they organize and they are used of the concepts of time and temporality in the exercise of his/her teaching. To build that reflection we will base our actions in a qualitative approach with triangulation of data, in that intended through interviews with the teachers to draw a profile of these professionals in what plays his/her professional and conceptual formation, for then we look for to understand how the construction of the concepts that those use in their educational activities happens. Another moment will consist of to analyze plannings and to observe the application of these in history classes. Finally through the reading of the activities (presents in the plannings) and of the evaluations developed by those teachers, in classroom, we will identify the multiples knowledge on time and temporality. To understand which the theoretical formation, as those teachers does their methodological choices and as starting from the temporality concepts they elaborate his/her informal (that elaborated in the daily of the educational action in the process teaching / learning) curriculum, he/she can aid to understand as he/she grows this process of teaching learning.

Keywords: Teaching of History; Historical education, School Culture; Time and Historical temporality.
\end{abstract}




\section{INTRODUÇÃO}

Uma das perguntas mais ouvidas pelos professores de História no exercício de sua atividade profissional em sala de aula é a finalidade do estudo desta disciplina já que, para muitos alunos, em sala são trabalhados apenas elementos do passado e a disciplina só se interessa por coisas de uma época em que a maioria deles e mesmo o próprio professor ainda nem existiam. Motivadas em encontrar uma resposta para essa questão e levando em conta esse contexto de presentismo, em que há excessos de informações, mas pouca reflexão sobre as mesmas durante as aulas de história, uma pesquisa realizada por Schmidt e Garcia (2006) pesquisadoras da UFPR no âmbito da educação histórica, com alunos que estudavam em escolas do Curitiba/PR procurava mostrar o interesse desses alunos pelas aulas e conteúdos de História. Com a pesquisa e a partir dos dados trazidos por essa investigação evidencia que "a maioria (dos alunos) concordou que era mais interessante e agradável aprender história pela televisão, pelo relato de pessoas idosas, ou mesmo lendo livros, do que as aulas, de onde não aprendiam nada que pudessem levar para sua própria vida" (2006, p.18).

Em outra pesquisa realizada por Rocha (2009) com alunos da educação básica, a pergunta orientadora era em torno das razões de se estudar história, tal pesquisa levou a conclusão de que as respostas tinham relação direta com concepções aprendidas sobre o tempo (passado/presente/futuro). Entre os alunos havia a compreensão de que estudariam História como um fim em si mesmo, parafraseando, em muitos casos, o que era dito por seus professores, como sendo o "estudo do passado", ou de um tempo remoto.

Neste sentido, acreditamos que compreender a existência de várias maneiras de conceber o tempo deve ser encarado como uma dimensão central da experiência humana, pois somente a partir desta noção que o homem pode estruturar seus pensamentos e ações. Para Bloch (1997) sendo a história a ciência dos homens no tempo fica claro que ao escrever sobre a história o historiador precisa pensar a questão da temporalidade envolvida neste processo, uma vez que:

O historiador não apenas pensa "humano". A atmosfera em que seu

pensamento respira
naturalmente é a
categoria da duração.
Decerto, dificilmente
imagina-se que uma
ciência, qualquer que seja,
possa abstrair do tempo.
Entretanto, para muitas
dentre elas, que, por
convenção, o desintegram
em fragmentos
artificialmente
homogêneos,
representa apenas uma
medida.
concreta e viva, submetida
à irreversibilidade de seu
impulso, o tempo da
história, ao contrário, é o
próprio plasma em que se
engastam os fenômenos e
como o lugar de sua
inteligibilidade. (BLoch,
1997, p.55)

Tendo essa distinção ao oficio do historiador, e aqui, pensando esse oficio no ato de ensinar, a disciplina História teria como função primordial o desenvolvimento do pensamento histórico. Para que, assim, ao debruçarmo-nos sobre as marcas deixadas pelos homens durante sua passagem pelo tempo não incorrêssemos em anacronismos $^{1}$ e julgamentos morais ou de valores.

Sobre o conceito de consciência histórica usamos a explicação proposta por Rüsen (2010) na qual o homem articula suas experiências em um trabalho intelectual para agir conforme uma orientação espaço-tempo que Ihe permita o que o autor chama de "orientação do agir (e do sofrer) humano no tempo" (RÜSEN, 2010, p.58). Alves (2011) usando o mesmo teórico, reafirma que a consciência histórica decorre do pensamento histórico uma vez que "todos, de alguma forma, pensam historicamente e aplicam esse pensamento na vida prática com o fim de compreender o sentido de suas vidas e dotar sua ação temporal de sentido" (2011, p.36).

Mas se, todos em algum momento pensam historicamente, (LEE, 2011; RÜSEN,

\footnotetext{
${ }^{1}$ De acordo com o dicionário Aurélio anacronismo pode ser: 1 Erro cronológico. 2 Coisa a que se atribui uma época em que ela não tinha razão de ser. Nesse sentindo usamos o termo como a falta de compreensão temporal (espaço-tempo) verificada em juízos de valor sobre esse ou aquele aspecto da passagem do homem no tempo.
} 
2010; ALVES, 2011) então, como caracterizar esse pensar como histórico?

Pensando o desenvolvimento do pensamento histórico em crianças Cainelli (2008) afirma que: "o desenvolvimento do pensamento histórico se articularia com o modo de pensar de cada criança a partir daquilo que lhe é significativo" (2008, p.99). Barca e Gago (2001) apontam que a compreensão dos conceitos históricos acontece a partir da relação desses com os conceitos da realidade social que o sujeito experiência e o pensar histórico ocorre "quando o aluno procura explicações para uma situação do passado à luz da sua própria experiência, mesmo sem apreciar as diferenças entre as suas crenças e valores e as de outra sociedade, revela já um esforço de compreensão histórica" (2001, p. 241).

Rüsen (2010) pensando, essa articulação entre pensar historicamente e as experiências temporais vividas pelo homem, aponta que 0 pensar historicamente pode ser visto da seguinte forma:

Ela consiste na articulação de experiências e intenções com respeito ao tempo (poder-seia mesmo falar de tempo interno e tempo externo): o homem organiza as intenções determinantes de seu agir de maneira que elas não sejam levadas ao absurdo no decurso do tempo. A consciência histórica é o trabalho intelectual realizado pelo homem para tornar suas intenções de agir conforme a experiência no tempo. Esse trabalho é efetuado na forma de interpretações das experiências do tempo... (RÜSEN, 2010, p.59).

Lee (2011) afirma que as ações do homem no tempo referem-se a eventos do passado, assim, "não podemos escapar de um tipo de passado. Mas podemos estar em condição de escolher que tipo de passado teremos" (2011, p.22), porém ele nos adverte que "historicidade é uma coisa e, história é outra" (LEE, 2011, p.22). Esse é uma premissa que deve estar presente no ensino de história. Para que evitemos um ensino de história que olhe para o passado apenas para criar padrões de significações importantes ao presente e que não possibilite um pensamento histórico real.

Pensando uma aula de história que possibilite o pensar histórico Schmidt e Cainelli (2010) apontam a importância do uso da categoria tempo em cada aula de história já que:

Ensinar história implica um trabalho diário com temporalidade. Em cada aula de história, há sempre um jogar com o tempo, isto é, pode-se viajar do presente para o passado mais próximo ou para um tempo mais remoto [...] Muitas vezes para fazer os alunos compreenderem melhor as temporalidades. (SCHMIDT; CAINELLI, 2010, p.97)

Pensando como os currículos escolares são elaborados, não raro, percebemos que a constituição/construção de um modelo de ensino está ligada a diversos interesses. Antoine Prost (2008), ao fazer um inventário da constituição da disciplina História no ensino francês, mostra como ela teve um papel fundamental na formação da própria sociedade daquele país, uma vez que "a história do ensino de História na França há de esclarecer-nos sobre a função específica que ela desempenha na sociedade francesa, assim como seu lugar ocupado na tradição francesa" (PROST, 2008, p.17). No caso brasileiro Circe Bittencourt (2009) aponta que o conteúdo de história, sempre esteve presente nas escolas brasileiras, porém sua importância aumenta a partir da 1870 quando começa a veicular uma história nacional.

Não é o objetivo deste artigo ou da pesquisa entender as transformações pelas quais o ensino de história passou ao longo dos anos, mas devemos dotar de historicidade nossa análise, uma vez que, mudanças sempre criam novos modelos e mecanismos de reprodução social e sendo a escola e a historiografia da história resultados da ação social essas mudanças refletem no trabalho do professor de história em seu cotidiano.

\section{PORQUE O TEMPO?}

Dado esse quadro inicial e o estabelecimento da categoria tempo como eixo central de nossa análise voltada ao ensino de História, tornou-se obrigatória nossa busca por normas que regem o Ensino de História em nosso 
país, essa busca nos levou a leitura dos Parâmetros Curriculares Nacionais ${ }^{2}$ (BRASIL, 2006) para o ensino de História.

Quando da leitura inicial dos Parâmetros para o ensino de História, constatamos a importância trazida por esse documento ao domínio do conceito de tempo, por essa razão já nós parece válida nossa intenção de pesquisa, já que, na atividade docente do historiador temos implícito o tratamento contínuo com as diferentes temporalidades e é preciso pensar sobre como elas têm se configurado nas práticas docentes.

Ao propor uma reflexão sobre a importância da categoria tempo no ensino de história, o documento (PCN) enfatiza que essa é fundamental, uma vez que: "as diversas dimensões de tempo só são compreendidas em todas suas complexidades pelo acesso dos alunos a conhecimentos adquiridos ao longo de uma variedade de estudos interdisciplinares durante sua escolaridade" (Brasil, 2006, p.98).

Assim, pensar a dimensão do que o ensino de História pode proporcionar na aprendizagem, deve ir muito além das narrativas históricas tradicionais, principalmente os "lugares comuns" de muitos livros didáticos e dos currículos padronizados, acreditamos que para que essa resposta inicial de o porquê de se estudar coisas passadas tem a ver com o fato de sermos membros de uma comunidade humana como bem nos lembra Hobsbawn (1998, p.22) "ser membro de uma comunidade humana é situar-se em relação ao seu passado (ou da comunidade)".

Outro fator que devemos considerar é que o conceito de tempo pode sofrer diversas interpretações por existirem diferentes formas de se pensar a relação entre passado e presente ou mesmo a relação tempo/temporalidade. Em uma aula de História, por exemplo, essas interpretações podem acontecer de acordo com as referencias teóricas, epistemológicas e metodológicas do professor ou mesmo a bagagem sobre a categoria que o aluno já possui.

\footnotetext{
2 De acordo com o site do Inep, os Parâmetros Curriculares nacionais (BRASIL, 2006) são: "são a referência básica para a elaboração das matrizes de referência [... ] e foram elaborados para difundir os princípios da reforma curricular e orientar os professores na busca de novas abordagens e metodologias apoiado em competências básicas para a inserção dos jovens na vida adulta; orientam os professores quanto ao significado do conhecimento escolar quando contextualizado e quanto à interdisciplinaridade, incentivando o raciocínio e a capacidade de aprender." Ver mais em: http://portal.inep.gov.br/web/saeb/parametros-curricularesnacionais
}

Nesse sentindo, entre as interpretações usuais em sala de aula sobre o passado podemos elencar as seguintes: 1- pensado enquanto explicador do presente; 2 - como construído pelas indagações do presente; 3 - desconectado do presente; 4 - como causa e efeito. Seja qual for a concepção com que se trabalhe, ela sempre implicará em riscos, como banalizações e possíveis anacronismos, assim como em diferentes formas de entender as diversas sociedades a partir de suas singularidades, conexões, simultaneidades e experiências.

Com a pesquisa esperamos perceber como o ato educativo é construído também por esses sujeitos (professores de História) e para isso, concordamos com Cool e Miras (1996), no entendimento de que é preciso perceber essa imbricada relação do professor com o conhecimento, partindo não somente do comportamento observável, mas também das cognições associadas aos mesmos, de suas formações acadêmicas e das experiências no contato com a comunidade escolar.

Motivados por essa questão entendemos ser preciso encontrar novas maneiras para que o ensino de História seja ressignificado, considerando a liquidez ${ }^{3}$ e os novos mecanismos de obtenção de informação em uma sociedade em que, segundo Juan Pozo (2004, p.02) "nunca houve tantas pessoas aprendendo tantas coisas ao mesmo tempo" e "na qual aprender constitui não apenas uma exigência social crescente [...] como também uma via indispensável para o desenvolvimento pessoal, cultural e mesmo econômico dos cidadãos".

\section{COMO CHEGAR "NO TEMPO" DOS PROFESSORES?}

Para entender o que é ensinado precisamos recorrer a uma dupla dimensão. A primeira reside no modelo pelo qual professor ensina os conceitos das ciências de referência, e aqui mais precisamente na forma utilizada por ele para mobilizar em seus planejamentos e aulas os conceitos históricos, como tempo/temporalidade histórica. A segunda é como esse conhecimento se organiza pela mediação da chamada cultura escolar que pode modificar ou configurar esses conceitos trazidos da ciência.

\footnotetext{
${ }^{3}$ Termo cunhado sociólogo polonês Zygmunt Bauman (2005) em que explica como a sociedade passa por momento de transformação em que as coisas são muito rápidas e não se moldam ou criam raízes.
} 
Sobre cultura escolar dialogamos com as ideias de Forquin (1993) Julia (2001) e Miranda (2007) em que a cultura escolar é vista como uma força formadora de hábitos a partir de processos específicos que (re)criam práticas escolares e a composição do saber, para tal faz-se necessário as relações cotidianas, as tradições curriculares, a organização do espaço escolar e a cultura material.

Forquin destaca que ao tratarmos de cultura temos duas extremidades de análise. Por um lado, uma acepção de cultura como conjunto de disposições do espírito, ou seja, aquela que possui um leque de conhecimentos e uma série de ações cognitivas. De outro lado temos o campo semântico da palavra que considera a cultura como um conjunto de características do próprio modo de vida em sociedade. Para ele:

Toda a reflexão sobre
educação e a cultura podem
assim partir da idéia segundo
a qual o que justifica
fundamentalmente, e sempre,
o empreendimento educativo
é a responsabilidade de ter
que transmitir e perpetuar a
experiênciar humana
considerada como cultura,
isto é, não como soma bruta
de tudo o que pode ser
realmente ser realmente
vivido, pensado, produzido
pelos homens desde o
começo dos tempos, pode
acender a uma existência
"pública", virtualmente
comunicável e memorável,
cristalizando-se nos saberes".
(Forquin. 1993, p.15)

Sobre esse contexto, Julia (2001, p. 1011) aponta que "normas e práticas não podem ser analisadas sem se levar em conta o corpo profissional dos agentes que são chamados a obedecer a essas ordens e, portanto, a utilizar dispositivos pedagógicos encarregados de facilitar sua aplicação". Assim esse projeto pretende se voltar às experiências dos docentes, levando em conta suas diversas experiências, fazeres e saberes que os motivam a fazer escolhas de conteúdos e procedimentos de ensino em torno do conceito de tempo, uma vez que não entendemos sua prática como mera transposição didática já que na educação histórica consideramos os conhecimentos trazidos por esses agentes da sala de aula, tanto professores quanto estudantes.

Sobre o que é ensinado Felgueiras (1994) acredita que a metodologia do ensino de história deve adequar-se aquilo que a sociedade espera, enquanto ação educativa, e também, as situações expressas na política de educação e nos objetivos gerais da disciplina para os respectivos graus de ensino. Há nesse sentido um movimentar-se para romper com uma realidade tecnicista e bancária de educação que para Freire (1996) passa por um testemunho do professor.

Por essa razão acima citada acreditamos ser importante pesquisar e compreender o significado e a importância que o professor dá para o uso do conceito de tempo e temporalidade histórica nas aulas de história do ensino regular. Sobre esse olhar do professor para o passado Rita Santos afirma que "pode-se perceber que o professor entende o passado de cunho prático como importante para o entendimento da sua disciplina. Ele entende que o passado tem o caráter de fornecer respostas a necessidades práticas da sua vida e a de seus alunos" (SANTOS, 2013, p.188)

\section{OBJETIVOS E METODOLOGIAS}

Antes de explicarmos de forma detalhada a metodologia deste trabalho e os objetivos que direcionam essa pesquisa gostaríamos de apresentar que tipo de ensino de história acreditamos ser possível, para isso, apoiamos nossa ação nas palavras de Cainelli (2008b) quando esta diz ser necessário uma pluralidade de saberes para a ação docente já que "em nosso entendimento, o resultado da ação pedagógica está intimamente relacionado á forma como o professor entende a ciência de referência e, consequentemente, aborda os conteúdos escolares" (CAINELLI, 2008b, p.136).

Assim nossa pesquisa tem como norte primordial compreender como professores de História, que ministram aulas nas redes municipal e estadual de ensino de Brasilândia/MS, constroem e entendem $o$ conceito de temporalidade histórica e estabelecem práticas didáticas no ensino de História a partir de sua formação.

Para alcançarmos esse objetivo metodologicamente recorremos a uma experiência já realizada por Cainelli (2008a) em que os resultados obtidos, tendo como referência os relatórios de estágio dos alunos/estagiários do curso de História da Universidade Estadual de 
Londrina, podem ser usados como base e modelo para pesquisa com os professores de história da rede municipal e estadual de Brasilândia, uma vez que ao fazer a análise sobre como estagiários constroem conhecimento histórico ela constatou que estes "acabam por vulgarizar o conhecimento histórico em nome de uma possível acessibilidade para os alunos" (2008a, p.137). Assim queremos perceber se o mesmo recurso é utilizado por esse grupo de análise no momento em elaboram seus planos de aulas e nos procedimentos didáticos em seu dia-a-dia.

Para compreendermos se esses procedimentos acima citados ocorrem ou deixam de ocorrer faremos uma análise partindo do conceito de triangulação de dados, que segundo Duarte (2009), possibilita ao pesquisador aferir usando diferentes técnicas de pesquisa a validade dos dados levantados. Adiante mostraremos outros objetivos buscados na pesquisa e as maneiras metodológicas propostas para chegarmos a esses dados e objetivos:

- Relacionar a prática docente com o uso de diferentes teorias sobre ensino e aprendizagem no âmbito do conhecimento histórico, assim como com suas experiências de vida fora de sala de aula.

Para esse objetivo passaremos por três etapas, a primeira por meio de questionário, tentaremos mapear o perfil profissional do docente de História em Brasilândia, feito isso, observaremos seus planejamentos e atividades que realizam em sala de aula para compreendermos como seu perfil pode ser aliado a sua prática e por fim, partindo das abordagens qualitativas inspiradas no princípio da etnografia de tipo escolar proposta por André (1995), utilizaremos a técnica de observação de aulas, caderno de campo e descrição densa onde buscaremos perceber de que maneira esses professores fazem a mediação didática desse conhecimento no processo de construção de conhecimento em suas aulas de história.

Ao analisarmos os planejamentos desse grupo de professores, o fazemos, buscando também identificar quais os múltiplos conhecimentos sobre tempo e temporalidade que eles possuem.

Por fim por meio de entrevistas almejamos mostrar a trajetória intelectual e formativa nas suas histórias de vida, que os levou a construir determinados conceitos de história e de tempo, concretizados em suas práticas de ensino.

\section{O TEMPO DO TEMPO - UMA SEMI-CONCLUSÃO}

Já vimos que a história enquanto disciplina escolar produz um conhecimento coletivo. Desta forma, a disciplina escolar não é somente uma mera forma de transpor conhecimentos com maior ou menor eficiência. Por outro lado, mesmo uma pesquisa na área de ensino, é uma pesquisa empreendia por um sujeito que norteia sua reflexão a partir de suas experiências.

A história debruça-se sobre as marcas deixadas pelos homens, nesse sentindo o uso da categoria tempo têm papel fundamental na construção de um conhecimento histórico afim de que os alunos entendam como ao longo dessa viagem humana, as várias sociedades organizaram diversas formas de marcar a passagem do tempo, por vezes de forma cronológica, mas também como marca subjetiva, como a memória, para que se coloquem como sujeitos de sua vivência. Outro fator que devemos considerar no estudo do tempo é a própria dificuldade em conceituá-lo, pois pensálo exige alto grau de abstração.

\section{REFERENCIAS}

ANDRÉ, Marli Eliza Dalmazo Afonso de. Etnografia da prática escolar. Campinas: SP: Papirus, 1995.

ALVES, Ronaldo Cardoso. Aprender história com sentido para a vida: consciência histórica em estudantes brasileiros e portugueses. São Paulo, SP: [s.n.], 2011.

BARCA, Isabel; GAGO, Marília. Aprender a pensar em história: um estudo com alunos do 60 ano de escolaridade. Revista Portuguesa de Educação, Guimarães, v. 14, n. 1, 2001, p. 239-261.

BITTENCOURT, Circe Maria Fernandes. Ensino de história: fundamentos e métodos. São Paulo: Cortez, 2009.

BLOCH, March. Apologia da história ou o ofício do historiador. Rio de Janeiro, RJ: Jorge Zahar, 1997.

BRASIL. Ministério da Educação. Secretaria de Educação Básica. Parâmetros nacionais de qualidade para a educação infantil (PCN). Brasília, 2006. 
BAUMAN, Zygmunt. Identidade : entrevista a Benedetto Vecchi. Rio de Janeiro: J. Zahar, 2005.

CAINELLI. Marlene Rosa. Os saberes docentes de futuros professores de história: a especificidade do conceito de tempo. Revista Currículo sem Fronteiras, v.8, n. 2, 2008a.

A construção do pensamento histórico em aulas de história do ensino fundamental. Revista Tempos Históricos, v.12, 2008b, p. 97109.

CERTEAU, Michel de. A escrita da história. Rio de Janeiro, RJ: Forense Universitária, 1982.

COLL, César; MIRAS, Mariana. Desenvolvimento Psicológico e Educação. Psicologia da Educação, Porto Alegre, v.2, 1996.

DUARTE, Tereza. A possibilidade da investigação a 3: reflexões sobre triangulação (metodológica). Lisboa, PT: CIES e-Working Papers, 2009.

FELGUEIRAS, Margarida Louro. Pensar a história, repensar seu ensino: a disciplina de história no 3 응 ciclo do ensino básico, alguns princípios orientados da metodologia de ensino. Porto: Porto, 1994.

FORQUIN, Jean-Claude. Escola e cultura: as bases sociais e epistemológicas do conhecimento escolar. Porto Alegre: Artes Médicas, 1993.

FREIRE, Paulo. Pedagogia da autonomia. Rio de Janeiro: Paz na Terra, 1996.

HOBSBAWN, Eric. Sobre a história. São Paulo, SP: Companhia da Letras, 1998.

JULIA, Dominique. A cultura escolar como objeto histórico. Revista Brasileira de História da Educação, Campinas, n.1., 2001.

LEE, Peter. Por que aprender história. Educar em Revista, Curitiba, n. 42, 2011.

MIRANDA, Sonia Regina. Sob o signo da memória. São Paulo: Unesp, 2007.
POZO, Juan Ignacio. A sociedade da aprendizagem e $\mathrm{o}$ desafio de converter informação em conhecimento. Revista Pátio, v.8, ago./out. 2004

PROST, Antoine. Doze Lições sobre a história. Belo Horizonte: Autêntica, 2008.

ROCHA, Helenice. Aula de história: Que bagagem levar? In: ROCHA; MAGALHÃES; GONTIJO (org.) A escrita da história escolar: memória e historiografia. Rio de Janeiro, RJ: Fundação Getulio Vargas, 2009.

RÜSEN, Jörn. Razão da história: fundamentos da ciência histórica. Brasília, DF: Ed. Universidade de Brasília, 2010.

SANTOS, Rita de Cássia Gonçalves Pacheco dos. A significância do passado para professores de História. 2013. 262 f. Tese (Doutorado em Educação) - Universidade Federal do Paraná, Curitiba, 2013.

SCHMIDT, Maria Auxiliadora; GARCIA, Tânia Maria Braga. Pesquisas em Educação Histórica: algumas experiências. Revista Educar, Curitiba, esp., p. 11-31, 2006.

SCHMIDT, Maria Auxiliadora; CAINELLI, Marlene Rosa. Ensinar história. 2. ed. São Paulo: Abril, 2010.

Recebido para publicação em: 20/04/2016

Revisado em: 23/04/2016

Aceito em: 26/04/2016 